\title{
ATITUDE EMPREENDEDORA E DESEMPENHO ORGANIZACIONAL EM MICRO E PEQUENAS EMPRESAS: UM ESTUDO NO SETOR VAREJISTA DE CONFECÇÕES DE CURITIBA - PR
}

DOI: 1014211/regepe.v5i1.354

Artigo recebido em: 03/07/2015

Artigo aprovado em: 03/03/2016

\begin{abstract}
Elói Junior Damke - Universidade Estadual do Oeste do Paraná ${ }^{1}$ Joice Franciele W. Damke - Universidade Estadual do Oeste do Paraná ${ }^{2}$ Mohamed Mehdi Hijazi - Universidade Estadual do Oeste do Paraná ${ }^{3}$ Júlio Ricardo Benitez Universidade Estadual do Oeste do Paraná ${ }^{4}$ Luis Fernando Moreira- Universidade Estadual do Oeste do Paraná ${ }^{5}$
\end{abstract}

Resumo: Diversos estudos têm defendido a relação de dependência entre atitude empreendedora e desempenho organizacional, embora são raros os levantamentos que associam estas duas variáveis, em especial, traços atitudinais do empreendedor com o desempenho de pequenas empresas. Conjugando variáveis nessas dimensões, este estudo objetivou analisar a relação entre atitude empreendedora e desempenho organizacional de micro e pequenas empresas do setor varejista de confecções do município de Curitiba - PR. Os dados foram levantados em survey com 229 empresas e investigados por meio do teste qui quadrado e de análise de correlação de Pearson e revelaram grupos de empresas com níveis de atitude distintos e diferentes níveis de desempenho, embora as médias dos grupos atingiram valores considerados próximos. As análises de correlações não evidenciaram a relação direta entre atitude empreendedora e desempenho organizacional.

Palavras-chave: Empreendedorismo; Atitude Empreendedora; Desempenho Organizacional.

\section{ENTREPRENEURIAL ATTITUDE AND PERFORMANCE ORGANIZATIONAL IN MICRO AND SMALL ENTERPRISES: A STUDY IN RETAILER SECTOR OF CURITIBA CLOTHING - PR}

\begin{abstract}
Several studies have been defended the dependency relationship between entrepreneurial attitude and organizational performance, although are few surveys include both variables, in particular attitudinal traits of the entrepreneur with the

\footnotetext{
${ }^{1}$ Endereço: Av. Tarquínio Joslin dos Santos, 1300 - Foz do Iguaçu - PR - Brasil / CEP 85870-900. Email:eloi.damke@gmail.com

2 E-mail: joicewd@gmail.com

3 E-mail:mohamhijazi@gmail.com

${ }^{4}$ E-mail: julioricardobenitez@gmail.com

${ }^{5}$ E-mail: moreiralfm@gmail.com
}

DAMKE, E. JR; DAMKE, F. W.; HIJAZI. M. M.; BENITEZ, J. R.; MOREIRA, L. F. Atitude empreendedora e desempenho organizacional em micro e pequenas empresas: um estudo no setor varejista de confecções de Curitiba - PR. Revista de Empreendedorismo e

Gestão de Pequenas Empresas, v.5, n.1, 2016. 
performance of small businesses. Combining these dimensions variables, this study aimed to analyze the relationship between entrepreneurial attitude and organizational performance of micro and small retail companies of clothing in the city of Curitiba PR. The data were collected in the survey with 229 companies and investigated by the chi-squared test and Pearson correlation analysis. They revealed groups of companies with different attitude levels and different levels of performance, although the means of the groups reached values considered close. Correlations analysis showed no direct relationship between entrepreneurial attitude and organizational performance.

Keywords: Entrepreneurship; Entrepreneurial Attitude; Organizational Performance.

\section{Introdução}

O empreendedorismo tem sido tema recorrente de objeto de investigação na área de administração, embora recente no campo acadêmico. Os primeiros movimentos surgiram na década de 1940, a partir de pesquisas na Harvard Business School e com a criação da Internacional Council for Small Business em 1950. Desde então, o interesse pela academia tem sido crescente. Somente nos Estados Unidos, aproximadamente meia centena de periódicos técnico-científicos sobre empreendedorismo emergiram, indicando a expansão da temática no meio acadêmico (ALDRICH, 2000).

No Brasil, apesar de recente, atualmente parece haver uma consolidação do empreendedorismo como área do conhecimento com status científico, embora frequentes as críticas acerca das fragilidades teóricas, conceituais e metodológicas do campo (GIMENEZ; INÁCIO Jr.; SUNSIN, 2001; SOUZA, 2001).

Apesar das críticas, a literatura atual sobre empreendedorismo estabelece relativo consenso acerca das suas dimensões e características centrais: fundamentalmente, concentra seus esforços no plano comportamental, que por sua vez está relacionada a variáveis atitudinais, valores e traços psicológicos do empreendedor que influenciam a ação (MACIEL; DAMKE; CAMARGO, 2009; CARLAND et al., 1984; SHANE; VENKATARAMAN, 2000).

Diversos estudos têm demonstrado a relação entre atitude empreendedora e as influências que os dirigentes possuem sobre as estratégias, ambientes e 
estruturas, assim como a relação que empresas com orientação empreendedora possuem sobre o desempenho organizacional (MORRIS; SEXTON, 1996; WIKLUND; SHEPHERD, 2005; ZAHRA; COVIN, 1995).

Apesar de resultados demonstrando associações entre desempenho e comportamento empreendedor terem sido encontrados em diversas pesquisas, estudos protelando tal relação ainda restringem suas raízes no conceito de desempenho econômico ou no conceito de vantagem competitiva. Assim, mesmo perante as variadas formas de desempenho relacionadas ao construto empreendedorismo, evidencia-se a relação entre desempenho e comportamento/orientação empreendedora que, por sua vez, está relacionada a variáveis atitudinais do dirigente, dimensão proposta para este estudo (NAMAN; SLEVIN, 1993; WIKLUND; SHEPHERD, 2005).

Diante o exposto, este estudo buscou responder o seguinte problema de pesquisa: Quais níveis de atitude empreendedora associaram-se ao desempenho organizacional das micro e pequenas empresas do setor varejista de confecções de Curitiba - PR?

Para propor resposta a essa questão, o artigo estrutura-se em cinco seções adicionais a esta introdução: inicialmente, efetiva-se a definição conceitual do empreendedorismo, com enfoque especial para a questão da avaliação da atitude empreendedora e sua relação com o desempenho organizacional. A partir do enfoque teórico, estabelecem-se os delineamentos metodológicos para a realização desta pesquisa e apresentam-se os resultados, conclusões, limitações do estudo e recomendações para pesquisas futuras.

\section{Atitude Empreendedora}

O campo que versa sobre empreendedorismo e sua relação com a estratégia, ambiente e desempenho, tem evoluído nas duas últimas décadas. As empresas expostas a mudanças rápidas, hipercompetição, alta volatilidade dos negócios e desmassificação de alguns setores acompanhados de crescimento de outros, sugerem uma abordagem empreendedora no desenvolvimento da estratégia empreendedora e desempenho organizacional em micro e pequenas empresas: um estudo no setor varejista de confecções de Curitiba - PR. Revista de Empreendedorismo e

Gestão de Pequenas Empresas, v.5, n.1, 2016. 
como dimensão vital para o desempenho organizacional, especialmente em pequenas empresas (DESS; LUMPKIN; COVIN, 1997).

Segundo Bruyat e Julien (2001), o comportamento empreendedor não necessariamente se trata de ser ou não empreendedor, mas de se situar dentro de uma faixa de indivíduos mais ou menos empreendedores. O mesmo autor também observa que é uma tarefa difícil quantificar um atributo subjetivo, não havendo um teste ou instrumento universalmente aceito que possa caracterizar o estado da arte no campo.

Embora aparentemente subjetiva e de difícil quantificação, a variável atitude empreendedora tem sido objeto de diversos estudos. Em 1992, foi publicado um instrumento denominado Carland Entrepreneurship Indexa, a fim de permitir a caracterização de comportamentos empreendedores (CARLAND; CARLAND; HOY, 1992), sendo, atualmente, um dos instrumentos mais conhecido para mensurar os níveis de atitude empreendedora, tanto do ponto de vista acadêmico quanto empresarial.

A escala CEI é resultante de extensa pesquisa sobre as variáveis que conformam o construto empreendedorismo, idealizada pelos pesquisadores $\mathrm{Jim}$ e Joãnn Carland, reconhecidos internacionalmente como especialistas nesse campo. Segundo Carland, Carland e Hoy (1992) foi possível compor o modelo baseando-se em conceitos de escritores expoentes do empreendedorismo, tais como McClelland (1972), no estudo da realização, Brockhaus $(1980,1982)$, na propensão pelo risco dos empreendedores, Drucker (1987), em inovação, Myers e Briggs (1962), em tipologias cognitivas, nos estudos de características de personalidades empreendedoras de Borland (1974), Davids (1963), Dunkelberg e Cooper (1982), Gasse (1977), Hartman (1959) (CARLAND; CARLAND; HOY, 1992).

Em linhas gerais, Carland, Carland e Hoy (1992) enfatizam que a construção da escala permite $\mathrm{o}$ entendimento das diferentes categorias de empreendedores. A categorização dos indivíduos baseia-se nos objetivos esperados para o futuro empreendimento. Há empreendedores que veem a empresa como uma parte de suas vidas, que é importante para gerar o autoemprego e renda suficiente para ter liberdade para estar com a família e amigos.

DAMKE, E. JR; DAMKE, F. W.; HIJAZI. M. M.; BENITEZ, J. R.; MOREIRA, L. F. Atitude empreendedora e desempenho organizacional em micro e pequenas empresas: um estudo no setor varejista de confecções de Curitiba - PR. Revista de Empreendedorismo e

Gestão de Pequenas Empresas, v.5, n.1, 2016. 
Outros, conforme Carland, Carland e Hoy (1992) entendem e aspiram pelo reconhecimento da sociedade e riqueza. Estes indivíduos, aliados a um desejo de autonomia, colocam a empresa como parte central de suas vidas. Por fim, os com necessidade de realização mais acentuada dão muita importância ao exercício da liderança nos negócios, visando a construção de uma grande empresa no futuro.

Para Carland, Carland e Hoy (1992), o comportamento empreendedor é uma função de quatro elementos: (i) traços de personalidade: necessidade de realização e criatividade; (ii) propensão ao risco: indica tendência em aceitar situações de incerteza; (iii) propensão a inovação: comportamento de busca por produtos ou processos completamente diferentes daqueles existentes; e (iv) postura estratégica: manifesta-se ao identificar oportunidades, organizar e aplicar recursos, visando transformá-las em produtos ou serviços a serem disponibilizados no mercado.

Para mensurar a atitude empreendedora, Carland, Carland e Hoy (1992) propuseram uma escala denominada Carland Entrepreneurship Index (CEI). Esta escala considera a atitude empreendedora como um continuum entre valores de 0 a 33 pontos, resultando em três faixas: de microempreendedor ( 0 a 15) ao macroempreendedor (26 a 33), passando pela faixa intermediária de empreendedor (16 a 25).

A maior ou menor presença dos quatro elementos citados acima resultaria em uma das três categorias, conforme salientam Carland, Carland e Hoy (1992). Os mesmos autores entendem que um macroempreendedor visualiza sua atividade como um meio de mudar o seu setor e tornar-se um líder por meio do crescimento de seus negócios. Já um microempreendedor, gerencia um negócio que não deverá crescer, mas que poderá se tornar uma referência em seu contexto de abrangência. Para este empreendedor o seu negócio é a fonte de renda familiar ou para simplesmente estabelecer emprego familiar.

Para o macroempreendedor, o seu negócio é o centro de seu universo, mas para o microempreendedor, sua atividade é antes de mais nada uma fonte de renda, uma importante parte de sua vida, mas não a principal delas. Segundo Carland, Carland e Hoy (1992) e Inácio Junior e Gimenez (2004), muitos empreendedores se classificam em algum lugar entre essas duas posições. 
Finalmente, resultados demonstrando associações entre desempenho e comportamento empreendedor têm sido encontrados em diversas pesquisas. No entanto, aparentemente, tais estudos que têm protelado tal relação, ainda restringem suas raízes no conceito de desempenho econômico (HALL, 2004) ou no conceito de vantagem competitiva (BRITO; VASCONCELOS, 2004).

Mesmo perante as variadas formas de desempenho relacionadas ao construto empreendedorismo, existem evidências da relação entre desempenho e comportamento/orientação empreendedora (NAMAN; SLEVIN, 1993; WIKLUND; SHEPHERD, 2005), que, por sua vez, está relacionada a variáveis atitudinais, dimensão proposta para este estudo.

A próxima seção reserva-se a apresentar os delineamentos metodológicos desta pesquisa. A partir das características empreendedoras identificadas, da conceituação de indivíduo empreendedor e da definição de desempenho organizacional, pretende-se, através desta pesquisa de campo, coletar os fatos junto à realidade através de uma técnica de survey, identificar o potencial empreendedor de pequenos empresários do ramo de confecções de Curitiba - PR e verificar se há relação entre atitude empreendedora e desempenho organizacional.

\section{Articulando Atitude Empreendedora e Desempenho Organizacional}

As condições que configuram maiores resultados em termos de desempenho endereçam para um volume considerável de pesquisas teóricoempíricas, sendo que estas demonstram associações consistentes entre o alinhamento da estratégia às capacidades da organização com as exigências ambientais, desdobrando-se em desempenhos superiores (DAY; LORD, 1988; HAMBRICK; MASON, 1984; MILLER; TOULOUSE, 1986; JEMISON, 1987; POWEL, 1982).

De acordo com Gimenez (2000), na pequena empresa, a escolha estratégica é normalmente levada a cabo pelo dirigente, que em geral não sistematiza em sua organização o planejamento estratégico, nem tampouco o aprendizado obtido em ações estratégicas anteriores. Perspectivas cognitivas e deterministas do fenômeno empreendedora e desempenho organizacional em micro e pequenas empresas: um estudo no setor varejista de confecções de Curitiba - PR. Revista de Empreendedorismo e

Gestão de Pequenas Empresas, v.5, n.1, 2016. 
estratégia evidenciam-se nesse contexto organizacional. Desse modo, compreendese que o comportamento empreendedor é uma variável a ser considerada em um conjunto de dimensões que possam associar-se com o desempenho organizacional em pequenas empresas.

Para Filion (2004), a pessoa-chave nas operações de uma pequena empresa é o empreendedor. Ele mesmo cria e desenvolve a visão do seu negócio e a transforma em objetivos. As condições que configuram maiores resultados em termos de desempenho endereçam para um volume considerável de pesquisas teórico-empíricas, sendo que estas demonstram consistentes associações entre o alinhamento da estratégia às capacidades da organização com as exigências ambientais, desdobrando-se em desempenhos superiores (DAY; LORD, 1988; HAMBRICK; MASON, 1984; MILLER; TOULOUSE, 1986; JEMISON, 1987; POWEL, 1982).

Dentre um conjunto de pesquisas estabelecendo a relação entre orientação empreendedora e desempenho, Covin, Green e Slevin (2006) estudaram os efeitos que práticas de formação de estratégia têm sobre a relação entre orientação empreendedora da empresa e seu desempenho. Cabe salientar, conforme os mesmos autores observam, que a orientação empreendedora é um conceito que revela a preocupação estratégica com o crescimento e inovação.

Dessa forma, neste estudo, houve a intenção de verificar como o impacto da orientação empreendedora poderia ser influenciado pelo modo de formação de estratégia, pela capacidade de aprendizagem estratégica a partir de fracassos e pela maior participação dos colaboradores no desenvolvimento da estratégia.

Coletando dados em 110 pequenas empresas industriais localizadas em três estados norte-americanos, foi demonstrada a existência de uma relação positiva entre orientação empreendedora e crescimento de vendas e, por sua vez, no desempenho.

Em vertente complementar, Jogaratnam e Tse (2004), pesquisando hotéis localizados na China, Hong Kong, Malásia e Cingapura, por meio de um levantamento com 164 gerentes de hotéis, mais precisamente em um estudo sobre a abordagem empreendedora na administração hoteleira, evidenciaram que os 
hotéis cuja abordagem administrativa fosse empreendedora, ou seja, marcada por ações inovadoras, proativas e de maior risco, conseguiram um desempenho melhor que seus concorrentes mais conservadores.

A partir deste conjunto de trabalhos, é possível articular a relação entre comportamento empreendedor e desempenho. Contudo, faz-se necessário caracterizar conceitualmente a variável desempenho.

Sob o ponto de vista objetivo/analítico, Venkatraman e Ramanujam (1986) consideram que a variável desempenho é multidimensional e pode ser avaliada e classificada em três níveis: (a) financeiro: retorno sobre ativos, vendas e patrimônio líquido; (b); empresarial: participação de mercado, crescimento, diversificação e desenvolvimento de produto; e (c) efetividade organizacional: satisfação dos funcionários, qualidade dos produtos e responsabilidade social.

Nesse sentido, é possível admitir que algumas dimensões de desempenho são necessárias para uma avaliação mais confiável desta variável: (a) indicadores financeiros (CLAYCOMB; GERMAIN, 1997; DROGE; CLAYCOMB; GERMAIN, 2003); (b) de processos (SCOTT, 1998); e (c) de mercado (GIBSON; IVANCEVICH; DONNELY, 1981).

Em estudo seminal, procurando abarcar boa parte das dimensões consideradas relevantes na avaliação de desempenho organizacional, Maciel, Reinert e Camargo (2008) desenvolveram uma escala com os seguintes itens, de natureza subjetiva, para avaliação do desempenho: (a) desempenho em relação aos concorrentes; (b) satisfação em relação ao investimento; (c) crescimento das vendas; (d) crescimento/redução das atividades da organização; (e) indicador invertido em relação ao item d; (f) sucesso do negócio em relação aos concorrentes; (g) retorno financeiro; (h) probabilidade de sobrevivência no longo prazo.

Essa escala é, fundamentalmente, apoiada pela literatura acerca das discussões dos consensos e divergências quanto à mensuração do construto, em especial no que concerne ao uso de indicadores objetivos e subjetivos (BARNEY, 1996; CANEDO; KRUGLIANSKAS, 1999; CHAKRAVARTHY, 1986; DESS; ROBINSON, 1984; GIMENEZ, 2000; MENNA; ROSSI, 2001; NAMAN; SLEVIN, 
1993; VENKATRAMAN; PRESCOTT, 1990 apud MACIEL; REINERT; CAMARGO, 2008).

Expostos os pressupostos teóricos, articulando atitude empreendedora e desempenho organizacional e tomando por base os construtos propostos para esta pesquisa com o objetivo de avaliar as relações de dependência, a hipótese que orienta este estudo pode ser assim sintetizada: "o desempenho organizacional é resultante da atitude empreendedora dos dirigentes de pequenas empresas do setor varejista de confecções de Curitiba - PR".

Explicitados os antecedentes teóricos e hipótese que nortearam este estudo, é importante descrever os procedimentos metodológicos do trabalho.

\section{Procedimentos Metodológicos}

Esta pesquisa adotou os procedimentos de levantamento de dados (survey) para a obtenção dos dados. Neste sentido, a coleta foi implementada junto à população de micro e pequenas empresas do setor varejista de confecções Curitiba - PR. De uma população de 1.216 empresas cadastradas na Junta Comercial, 229 aderiram como amostra do estudo. Apesar de não probabilística, esta amostra proporcionou aderência aos critérios de amostragem estabelecidos por Hair et al. (2005), de que o número mínimo de observações por variáveis deve ser superior a cinco.

Para a coleta dos dados primários referentes à atitude empreendedora e desempenho organizacional, foram utilizadas escalas previamente testadas em outras pesquisas. Na primeira etapa da coleta, o instrumento buscou caracterizar o perfil da amostra; por conseguinte, para avaliar os níveis de atitude empreendedora - segunda etapa do questionário - utilizou-se do índice Carland Entrepreneurship Index(CEI) na versão em português (INÁCIO JÚNIOR; GIMENEZ, 2004). Finalmente, para a mensuração do desempenho, foi utilizada escala apresentada por Maciel, Reinert e Camargo (2008).

A análise dos dados baseou-se em técnicas estatísticas bivariadas, iniciando com a caracterização da amostra final do estudo. Em seguida, foi realizado o teste empreendedora e desempenho organizacional em micro e pequenas empresas: um estudo no setor varejista de confecções de Curitiba - PR. Revista de Empreendedorismo e

Gestão de Pequenas Empresas, v.5, n.1, 2016. 
do quiquadrado a fim de verificar se há uma associação significativa entre as variáveis nominais e comparar, caso haja divergências, as frequências observadas e esperadas para certo evento, uma vez que esta pesquisa teve como objetivo, averiguar e comparar a frequência das empresas com baixo e médio nível de atitude empreendedora com a variável desempenho.

Por fim, foi realizado o teste de correlação de Pearson para de medir o grau de relação linear entre as variáveis, ou seja, se as alterações que uma variável sofre são acompanhadas por alterações na outra variável estudada. Neste estudo, a correlação foi utilizada para apurar se há uma relação funcional entre a variável atitude empreendedora e a desempenho, ou seja, se ocorrem modificações no desempenho da empresa quando verificado o baixo nível empreendedor, por exemplo.

Apresentados os aspectos teóricos e metodológicos que nortearam este estudo, em seguida efetivam-se as análises e apresentação dos resultados obtidos na pesquisa.

\section{Apresentação e Análise dos Dados}

$\mathrm{Na}$ primeira parte desta seção, são apresentadas as características sociodemográficas dos pesquisados que compuseram a amostra do estudo. Do total dos 229 casos válidos, constatou-se forte presença feminina na função de dirigentes - 169 casos. Na sequência, buscou-se caracterizar o perfil geral das empresas pesquisadas: empresas recém-fundadas com um mês de existência, até empresas com pouco mais de 60 anos foram encontradas.

No entanto, foi verificado que as empresas são, em sua maioria, relativamente novas, com uma média de 8,89 anos de existência, com média de 5,10 empregados por empresa. O tempo de experiência dos dirigentes, por sua vez, demonstrou que, na média, os dirigentes possuíam 7,36 anos de trabalho. Essas características podem ser visualizadas na Tabela 1.

DAMKE, E. JR; DAMKE, F. W.; HIJAZI. M. M.; BENITEZ, J. R.; MOREIRA, L. F. Atitude empreendedora e desempenho organizacional em micro e pequenas empresas: um estudo no setor varejista de confecções de Curitiba - PR. Revista de Empreendedorismo e

Gestão de Pequenas Empresas, v.5, n.1, 2016. 
TABELA 1 - CARACTERÍSTICAS GERAIS DAS EMPRESAS PESQUISADAS

\begin{tabular}{ccccc}
\hline Variável & Mínimo & Máximo & Média & $\begin{array}{c}\text { Desvio } \\
\text { Padrão }\end{array}$ \\
\hline Anos da Empresa & 0,10 & 60,60 & 8,89 & 9,25 \\
Número de Empregados & 1,00 & 40,00 & 5,10 & 5,91 \\
Tempo Trabalho do & 0,10 & 45,20 & 7,36 & 7,68 \\
$\quad$ Dirigente & & & & \\
\hline FONTE: Os autores (2016. & & & &
\end{tabular}

Caracterizado o perfil da amostra, conforme apontado na seção anterior, o próximo passo foi verificar os níveis de atitude empreendedora encontrados.

Conforme pode ser apreciado no Quadro 1, do total das 229 empresas pesquisadas, dois grupos com níveis de atitude empreendedora distintos foram encontrados: 83 empresas inseriram-se na faixa microempreendedor e 146 empresas na faixa intermediária. Somente 1 caso isolado de comportamento macro foi encontrado no estudo.

Por conseguinte, realizaram-se os testes quiquadrado e de correlação de Pearson. O teste quiquadrado, conforme mencionado na metodologia deste trabalho, foi utilizado a fim de verificar se houve associação significativa entre as variáveis nominais.

No teste quiquadrado, a variável desempenho foi classificada como variável dependente, enquanto a variável atitude empreendedora foi classificada como variável independente. Como resultado, o valor- $p$ obtido, destacado abaixo, foi superior ao nível de significância de 5\%, aceitando a hipótese nula de que não existe diferença de frequência entre os grupos. Não sendo diferentes das frequências esperadas, concluiu-se que não há associação entre os grupos e, portanto, nesta instância, associação entre atitude empreendedora e desempenho organizacional. Os resultados pormenorizados estão no Quadro 1:

QUADRO 1 - TESTE QUIQUADRADO

\begin{tabular}{|c|c|c|c|c|c|}
\hline & Value & df & $\begin{array}{l}\text { Asymp. Sig. } \\
\text { (2-sided) }\end{array}$ & $\begin{array}{l}\text { ExactSig. (2- } \\
\text { sided) }\end{array}$ & $\begin{array}{l}\text { ExactSig. (1- } \\
\text { sided) }\end{array}$ \\
\hline Pearson Chi-Square & ,399 & 1 & ,528 & & \\
\hline ContinuityCorrection ${ }^{b}$ & 206 & $\overline{11}$ & 650 & & \\
\hline LikelihoodRatio & ,394 & $\overline{11}$ & ,530 & & \\
\hline Fisher'sExact Test & & & & ,595 & 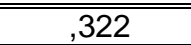 \\
\hline $\begin{array}{l}\text { Linear-by-Linear } \\
\text { Association }\end{array}$ & 397 & 1 & ,529 & & \\
\hline $\bar{N}$ ofValid Cases & 229 & & & & \\
\hline
\end{tabular}

FONTE: Os autores (2016)

DAMKE, E. JR; DAMKE, F. W.; HIJAZI. M. M.; BENITEZ, J. R.; MOREIRA, L. F. Atitude empreendedora e desempenho organizacional em micro e pequenas empresas: um estudo no setor varejista de confecções de Curitiba - PR. Revista de Empreendedorismo e Gestão de Pequenas Empresas, v.5, n.1, 2016. 
Portanto, tal resultado evidencia a não existência estatística da relação entre atitude empreendedora e desempenho organizacional devido ao rendimento próximo de ambos os grupos, microempreendedor e intermediário, haja vista que cerca de $82 \%$ das 229 observações que compõem a amostra obtiveram um bom desempenho, como segue na tabela 2:

TABELA 2 - RESULTADOS DO DESEMPENHO POR GRUPO DE COMPORTAMENTO

\begin{tabular}{ccccc}
\hline CASOS & ATITUDE & DESEMPENHO & $\begin{array}{c}\text { MÉDIA INDIVIDUAL DE } \\
\text { DESEMPENHO }\end{array}$ & $\begin{array}{c}\text { MÉDIA POR } \\
\text { GRUPO }\end{array}$ \\
\hline 17 & Microempreendedor & Ruim & 3,183 & 4,882 \\
66 & Microempreendedor & Bom & 5,320 & \\
25 & Intermediário & Ruim & 3,325 & 4,913 \\
121 & Intermediário & Bom & 5,241 & \\
\hline
\end{tabular}

FONTE: Os autores (2016)

Neste estudo, as empresas que obtiveram desempenho inferior ou igual a quatro foram consideradas com desempenho ruim. Já as empresas que obtiveram desempenho superior a quatro foram consideradas de bom desempenho. A média individual calculada foi baseada apenas nas observações de características (atitude e desempenho) específicas. Já a média por grupo foi calculada adotando todas as observações de cada grupo (microempreendedor e intermediário), seja de ruim ou bom rendimento organizacional.

Por meio da correlação de Pearson, obtida ao nível de significância de 0,05, as amostras das observações classificadas como microempreendedores e as observações classificadas como faixa intermediária de empreendedores foram analisadas de forma individual, conforme ilustrados no quadro abaixo a partir dos gráficos de dispersão da correlação de cada grupo: 
FIGURA 1- GRÁFICOS DE DISPERSÃO DA CORRELAÇÃO DE PEARSON
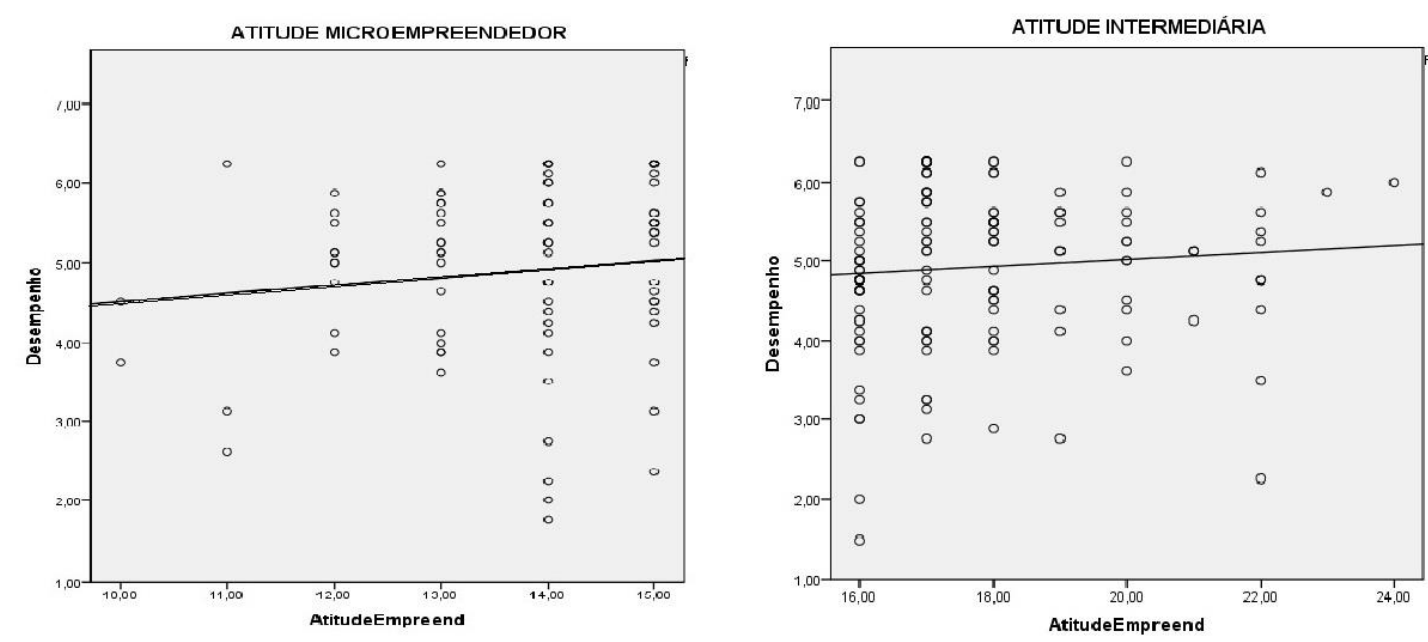

FONTE: Os autores (2016).

De acordo com Hair et al. (2005), o valor do coeficiente de correlação possui força associativa quando for estatisticamente significativo. Neste estudo, o coeficiente de correlação do grupo das observações consideradas microempreendedoras obteve o valor 0,122, enquanto o grupo das observações consideradas de nível empreendedor intermediário obteve 0,086.

Ambos os resultados obtidos foram considerados de correlação leve, quase imperceptível quando relacionados com a variável analisada (desempenho), conforme afirma Hair et al. (2005). Isto é, quando os valores do coeficiente estão compreendidos entre 0,01 e 0,20. Quando analisadas de forma universal, também foi verificada a correlação quase imperceptível entre as variáveis analisadas, uma vez que o coeficiente obtido foi de 0,072.

A observação considerada como atitude macroempreendedora foi excluída destes testes estatísticos devido ao número pouco significante na amostra original de 229 observações, pois apenas uma observação foi considerada como macroempreendedora.

Tais resultados evidenciam a não existência associativa entre a variável dependente e a variável independente. A relação linear existente entre elas é considerada praticamente imperceptível, refutando a hipótese deste estudo de que o 
desempenho organizacional é resultante da atitude empreendedora dos dirigentes de pequenas empresas do setor varejista de confecções de Curitiba - PR.

\section{Considerações Finais}

Um número considerável de perspectivas teóricas tem provido insights importantes na descrição da relação entre comportamento empreendedor e desempenho organizacional. Contudo, grande parte deles, tradicionalmente, senão em sua maioria, tem demonstrado as relações com desempenho a partir de combinações unidirecionais e sumarizadas.

Nesse sentido, o presente estudo direcionou seus esforços no plano comportamental do empreendedorismo, buscando verificar quais níveis de atitude empreendedora associaram-se ao desempenho das micro e pequenas empresas do setor varejista de confecções de Curitiba - PR. Este objetivo geral desdobrou-se na problematização da pesquisa.

Com base nos resultados, foi possível constatar a não relação unidimensional destes construtos. Embora os resultados não corroboraram a hipótese deste estudo, cabe salientar que diversas pesquisas têm demonstrado relações multivariadas com o desempenho, ou seja, um conjunto de dimensões e, dentre elas, o comportamento empreendedor, influenciando maiores níveis de desempenho. Como exemplo, pode-se citar a abordagem das configurações proposta por Miller (1987a, 1987b), onde a liderança é um dos quatro imperativos defendido por esta perspectiva, que demonstra relações multivariadas impactando no desempenho organizacional.

Em estudo realizado por Damke e Gimenez (2014), pesquisando 230 empresas do setor varejista de confecções de Curitiba - PR, por exemplo, verificouse que o desempenho destas organizações era dependente de um conjunto de dimensões compostas por condições ambientais, estruturais, de processo, conteúdo estratégico e comportamento empreendedor do dirigente. Essas dimensões são defendidas pela abordagem das configurações proposta por Miller (1987a) e posteriormente defendida por diversos outros pesquisadores (HAMBRICK; MASON, empreendedora e desempenho organizacional em micro e pequenas empresas: um estudo no setor varejista de confecções de Curitiba - PR. Revista de Empreendedorismo e

Gestão de Pequenas Empresas, v.5, n.1, 2016. 
1984; MILLER; FRIESEN, 1978, 1984; TUSHMAN; ROMANELLI, 1985, entre outros).

Desse modo, destaca-se o comportamento empreendedor como variável indissociável dentro de uma estrutura integrada que se relaciona com o desempenho organizacional, em especial, de pequenas empresas. No estudo de Damke e Gimenez (2014), anteriormente citado, a variável com maior peso na explicação do desempenho das organizações pesquisadas foi a atitude empreendedora do dirigente, resultado consistente com a abordagem das configurações e que demonstra a relevância da atitude empreendedora como variável indissociável na explicação de melhores níveis de desempenho.

Convém ressaltar nesta instância, as contribuições advindas desta pesquisa, em especial, do ponto de vista da práxis empresarial. Considerando que a gestão em pequenas empresas é altamente dependente de um ator principal, acredita-se que ampliando os conhecimentos desses atores, melhores resultados poderão ser alcançados, uma vez que este estudo demonstrou a relação da não unidimensionalidade na explicação do desempenho de pequenas organizações.

Por fim, elencam-se as limitações deste estudo. Como o objetivo da pesquisa foi avaliar a relação entre atitude empreendedora e desempenho de pequenas empresas do setor de confecções, outros estudos utilizando a mesma metodologia poderiam ser realizados em outros setores econômicos para reforçar as conclusões deste trabalho.

Destarte, outro fator limitador refere-se à avaliação do construto desempenho perceptualmente, ou seja, através da utilização de escala com indicadores subjetivos. Novos estudos poderiam ser realizados congregando indicadores objetivos e subjetivos. Tais limitações poderiam ser consideradas direcionamentos importantes para pesquisas futuras que tratem desta instigante abordagem adotada para este estudo.

\section{Referências:}

ALDRICH, H. E. Entrepreneurial Strategies in New Organizational Populations. In SWEDBERG, Richard. Entrepreneurship. The Social Science View. Oxford: University Press, 2000.

DAMKE, E. JR; DAMKE, F. W.; HIJAZI. M. M.; BENITEZ, J. R.; MOREIRA, L. F. Atitude empreendedora e desempenho organizacional em micro e pequenas empresas: um estudo no setor varejista de confecções de Curitiba - PR. Revista de Empreendedorismo e

Gestão de Pequenas Empresas, v.5, n.1, 2016. 
BARNEY, J. B. Gaining and sustaining competitive advantage. 2nd ed. Massachusetts: Addison-Wesley Publishing Company, 1996.

BRITO, L. A. L.; VASCONCELOS, F. C. A heterogeneidade do desempenho, suas causas e o conceito de vantagem competitiva: proposta de uma métrica. Revista de Administração Contemporânea, v. 8, Edição Especial, 2004.

BROCKHAUS, R. H. The psychology of the entrepreneur. In: KENT, C. A.; of SEXTON, D. L.; VESPER, K. H. (Ed.) Encyclopedia Entrepreneurship. New Jersey: Prentice-Hall, 1982. p. 39-71.

BRUYAT, C.; JULIEN, P. A. Defining the field of research in entrepreneurship. Journal of Business Venturing, v. 16, n. 2, p. 165-180, 2001.

CANEDO, M. T. P.; KRUGLIANSKAS, I. Perfil do empreendedor e conhecimento sobre o cliente como condicionantes do desempenho de supermercados. In: ANGELO, C. F.; SILVEIRA, J. A. G. (Coord.). Varejo competitivo. São Paulo: Atlas, 1999. p. $130-148$.

CARLAND, J. W.; HOY, F.; BOULTON, W. R.; CARLAND, J. A. C. Differentiating entrepreneurs from small business owners: a conceptualization. Academy of Management Review, v. 9, n. 2, p. 354-359, 1984.

CARLAND, J. W.; CARLAND, J. A.; HOY, F.. An entrepreneurship Index: an empirical validation. Frontiers of Entrepreneurship Research, v. 25, n. 3, p. 244265, 1992.

CHAKRAVARTHY, B. S. Measuring strategic performance. Strategic Management Journal, v. 7, n. 5, p. 437-458, 1986.

CLAYCOMB, C.; GERMAIN, R. Organizational learning and performance: an empirical test. In: American marketing association winter educators conference. Conference... Saint Petersburg. Saint Petersburg: AMA, 1997, p. 94-100.

COVIN, J. G; GREEN, K. M.; SLEVIN, D. P. Strategic Process Effects on the Entrepreneurial Orientation-Sales Growth Rate Relationship. Entrepreneurship Theory and Practice, v. 30, n. 1, p. 56-81, 2006.

DAMKE, E. J.; GIMENEZ, F. A. P. Configurações estratégicas e desempenho organizacional: um estudo em Micro e Pequenas empresas do setor de varejo. In: XXXVIII ENANPAD, 38, 2014, Rio de Janeiro. Anais... Rio de Janeiro: Anpad, 2014.

DAY, D. V.; LORD, R. Executive leadership and organizational performance: Suggestions for a new theory and methodology. Journal of Management, v. 14, n. 3, p. 453-464, 1988.

DAMKE, E. JR; DAMKE, F. W.; HIJAZI. M. M.; BENITEZ, J. R.; MOREIRA, L. F. Atitude empreendedora e desempenho organizacional em micro e pequenas empresas: um estudo no setor varejista de confecções de Curitiba - PR. Revista de Empreendedorismo e

Gestão de Pequenas Empresas, v.5, n.1, 2016. 
DESS, G.; LUMPKIN, G. J.; COVIN, J. G. Entrepreneurial strategy making and firm performance: tests of contingency and configurational models. Strategic Management Journal, v. 18, n. 9, p. 677-695, 1997.

DESS, G. G.; ROBINSON Jr., R. B. Measuring organizational performance in the absence of objective measures: the case of the privately-held firm and conglomerate business unit. Strategic Management Journal, v. 5, n. 3, p. 265-275, 1984.

DROGE, C.; CLAYCOMB, C.; GERMAIN, R. Does knowledge mediate the effect of context on performance? Some inicial evidence. Decision Sciences, v. 34, n.3, p. 541-568, 2003.

DRUCKER, P. F. Inovação e espírito empreendedor. São Paulo: Pioneira, 1987.

FILION, L. J. Operators and Visionaries: Differences in the Entrepreneurial and Managerial Systems of two Types of Entrepreneurs. International Journal of Entrepreneurship and Small Business, v. 1, n. 1-2, p. 35-55, 2004.

INÁCIO JUNIOR, E.; GIMENEZ, F. A. P. Potencial empreendedor: um instrumento para mensuração. Revista de Negócios, v. 9, n. 2, p. 107-116, 2004.

GIBSON, J. L.; IVANCEVICH, J. M; DONNELY, J. H. Organizações. São Paulo: Atlas, 1981.

GIMENEZ, F. A. P.; INÁCIO JUNIOR, E.; SUNSIN, L. A. de S. B. Uma Investigação Sobre a Tendência do Comportamento Empreendedor. In: SOUZA, E. C. L. de (Org.). Empreendedorismo. Competência essencial para pequenas e médias empresas. Brasília: ANPROTEC, 2001, p. 9-24.

GIMENEZ, F. A. P. O estrategista na pequena empresa. Maringá, 2000.

HAIR, J. F. et al. Análise multivariada de dados. 5. ed. Porto Alegre: Bookman, 2005.

HALL, R. H. Organizações: estruturas, processos e resultados. São Paulo: Prentice Hall, 2004.

HAMBRICK, D. C.; MASON, P. A. Upper echelons: The organization as a reflection of its top managers. Academy of Management Review, v. 9, n. 2, p. 193-206, 1984.

INÁCIO JÚNIOR, E; GIMENEZ, F. A. P. Potencial empreendedor: um instrumento para mensuração. Revista de Negócios, v. 9, n. 2, 2004.

JEMINSON, D. B. Risk and the relationship among strategy development. Long Range Planning, v. 26, n. 5, p. 132-137, 1987.

DAMKE, E. JR; DAMKE, F. W.; HIJAZI. M. M.; BENITEZ, J. R.; MOREIRA, L. F. Atitude empreendedora e desempenho organizacional em micro e pequenas empresas: um estudo no setor varejista de confecções de Curitiba - PR. Revista de Empreendedorismo e

Gestão de Pequenas Empresas, v.5, n.1, 2016. 
JOGARATNAM, G.; TSE, E. C-Y. The entrepreneurial approach to hotel operation: evidence from the Ásia-Pacific hotel industry. Cornell Hotel and Restaurant Administration Quarterly, v. 45, n. 3, p. 248-259, 2004.

MACIEL, C. O.; DAMKE, E. J.; CAMARGO, C. Abordagem das configurações nos estudos em empreendedorismo: críticas, oportunidades e desafios metodológicos. Perspectivas Contemporâneas, v. 4, n. 2, p. 38-57, 2009.

MACIEL, C. O.; REINERT, M.; CAMARGO, C. Configurações estratégicas e desempenho organizacional: em busca de novos imperativos. REBRAE: Revista Brasileira de Estratégia, v. 1, n. 2, p. 199-212, 2008.

MCCLELLAND, D. A sociedade competitiva: realização e progresso social. Rio de Janeiro: Expressão e Cultura, 1972.

MENNA, H. L.; ROSSI, C. A. V. Orientação para o mercado e performance: evidências em empresas gaúchas de varejo de confecções masculinas. In: ANGELO, C. F.; SILVEIRA, J. A. G. (Coord.). Varejo competitivo. São Paulo: Atlas, 2001. p. 154-177.

MILLER, D. Strategy Making and Structure: analysis and implications for performance. Academy of Management Journal, v. 30, n.1, p. 7-32, 1987a.

, D. The genesis of configuration. Academy of Management Review, v. 12, n.4, p. 686-701, 1987b.

MILLER, D.; FRIESEN, P. H. Archetypes of strategy formulation. Management Science, 24: 921-933, 1978.

MILLER, M.; TOULOUSE, J. Chief executive personality and corporate strategy and structure in small firm. Management Science, v. 32, n. 11, p. 1388-1409, 1986.

MORRIS, M. H.; SEXTON, D. L. The concept of entrepreneurial intensity: Implications for company performance. Journal of Business Research, v. 36, n. 1, p. 5-13, 1996.

MYERS, L. B. Manual: The Myers-Briggs Type Indicator. Princeton: Educational Testing Services, 1962.

NAMAN, J. L.; SLEVIN, D. P. Entrepreneurship and the concept of fit: a model and empirical tests. Strategic Management Journal, v. 14, n. 2, p. 137-153, 1993.

POWEL, T. C. Strategic planning as competitive advantage. Strategic Management Journal, v. 13, n. 7, p. 551-558, 1982.

DAMKE, E. JR; DAMKE, F. W.; HIJAZI. M. M.; BENITEZ, J. R.; MOREIRA, L. F. Atitude empreendedora e desempenho organizacional em micro e pequenas empresas: um estudo no setor varejista de confecções de Curitiba - PR. Revista de Empreendedorismo e

Gestão de Pequenas Empresas, v.5, n.1, 2016. 
SCOT, W. R. Organizations: rational, natural and open systems. 4. ed. New Jersey: Prentice Hall, 1998.

SHANE, S.; VENKATARAMAN, S. The promise of entrepreneurship as a field of research. Academy of Management Review, v. 25, n. 1, p. 217-226, 2000.

SOUZA, E. C. L. de. A Disseminação da Cultura Empreendedora e a Mudança na Relação Universidade-Empresa. In: Souza, Eda C. L. de (Org.). Empreendedorismo: competência essencial para pequenas e médias empresas. Brasília: ANPROTEC, 2001, p. 28-41.

TUSHMAN, M.; ROMANELLI, E. Organizational evolution: a metamorphosis model of convergence and reorientation. In: CUMMINGS, L.; STAW, B. M. Research in organizational behavior, v. 7, 171-222. Greenwich, Conn.: JAI Press, 1995.

WIKLUND, J.; SHEPHERD, D. Entrepreneurial orientation and small business performance: A configurational approach. Journal of Business Venturing, v. 20, n. 1, p. 71-91, 2005.

VENKATRAMAN, N; PRESCOTT, J. E. Environment-strategy coalignment: an empirical test of its performance implications. Strategic Management Journal, v. 11, n. 1, p. 1-23, 1990.

VENKATRAMAN, N.; RAMANUJAM, V. Measuring of business performance in strategy research: a comparison approaches. Academy of management review, $\mathrm{v}$. 11, n. 4, p. 801-814, 1986.

ZAHRA, S. A.; COVIN, J. G. Contextual influences on the corporate entrepreneurship-performance relationship: A longitudinal analysis. Journal of Business Venturing, v. 10, n. 1, p. 43-58, 2005.

' Artigo indicado no fast track do SemeAd 2015.

DAMKE, E. JR; DAMKE, F. W.; HIJAZI. M. M.; BENITEZ, J. R.; MOREIRA, L. F. Atitude empreendedora e desempenho organizacional em micro e pequenas empresas: um estudo no setor varejista de confecções de Curitiba - PR. Revista de Empreendedorismo e Gestão de Pequenas Empresas, v.5, n.1, 2016. 